\title{
Coisa Julgada, ação rescisória e o princípio da estabilização das decisões judiciais
}

\author{
Res judicata, rescissory action and the stabilizing of judicial decisions principle \\ Cosa juzgada, acción de rescisión y principio de estabilización de las decisiones judiciales
}

Recebido: 20/10/2021 | Revisado: 27/10/2021 | Aceito: 31/10/2021 | Publicado: 02/11/2021

\author{
Alessandra Frei Silva \\ ORCID: https://orcid.org/0000-0002-0542-2451 \\ Universidade Paranaense, Brasil \\ E-mail: alessandrafrei@gmail.com
}

\begin{abstract}
Resumo
No presente artigo serão analisados os meios pelos quais o ato jurídico pode adquirir a estabilidade, sendo eles a estabilização, preclusão e coisa julgada, de forma que será definida a diferença entre esses três institutos, bem como será estudada a importância da estabilidade do ato jurídico para o ordenamento processual civil brasileiro, a relevância do princípio da estabilização das decisões judiciais e também serão abordados aspectos da Ação Rescisória, sua natureza jurídica e as suas hipóteses de aplicação descritas no rol taxativo do diploma processual, especialmente no que diz respeito ao impacto dessa ação quanto à estabilização das decisões judiciais no sentido de se analisar se a Ação Rescisória rompe ou não com a segurança e estabilidade que se espera do ato jurídico, verificando-se também que a ação rescisória é dotada de importância porquanto protege o ordenamento jurídico e também corrige injustiças, concluindo-se que não há que se falar em afronta à segurança jurídica.
\end{abstract}

Palavras-chave: Estabilização; Ação rescisória; Segurança.

\begin{abstract}
In the presente article will be analized the means by which the legal act may acquire the stability, that are the stabilization, preclusion and res judicata, so that will be defined the difference between these three institutes, as well as the importance of the stability of the legal act for the brasilian civil procedural order will be studied, the relevance of the principle of stabilisation of judicial decisions and aspects of the Rescission Action, its legal nature and its hypotheses of application described in the tax roll of the procedural legislation, especially with regard to the impact of such action on the stabilisation of judicial decisions in order to examine whether or not the Rescission Action breaks the security and stability expected of the legal act, it is verified also that the rescission action is endorsed with importance because it protects the legal system and also corrects injustices, concluding that there is no need to speak of an affront to legal security.
\end{abstract}

Keywords: Stabilization; Rescissory action; Security.

\section{Resumen}

Este artículo analizará los medios por los cuales el acto jurídico puede adquirir estabilidad, que es la estabilización, la preclusión y algo juzgado, de modo que se definirá la diferencia entre estos tres institutos, así como la importancia de la estabilidad del acto jurídico para el orden procesal civil brasileño, la relevancia del principio de estabilización de las decisiones judiciales, y también se abordarán aspectos de la Acción de Rescisión, su naturaleza jurídica y sus hipótesis de aplicación descritas en el padrón fiscal de la legislación procesal, especialmente en lo que respecta al impacto de esta acción en la estabilización de las decisiones judiciales con el fin de examinar si la Acción de Rescisión rompe o no la seguridad y estabilidad esperadas del acto jurídico, también se verifica que la acción de rescisión está refrendada con importancia porque protege el ordenamiento jurídico y también corrige injusticias, concluyendo que no hace falta hablar de una afrenta a la seguridad jurídica.

Palabras clave: Estabilización; Acción de rescisión; Seguridad.

\section{Introdução}

O artigo busca analisar as formas pelas quais o ato jurídico adquire a estabilidade, sendo elas a preclusão, estabilização e coisa julgada, sendo a estabilidade uma exigência de segurança jurídica.

Para que haja compreensão no que diz respeito ao instituto da coisa julgada e consequentemente seja analisado se há uma estabilidade relativa da decisão judicial quando da ação rescisória, é importante traçar alguns aspectos importantes acerca das formas pelas quais o ato jurídico adquire estabilidade, motivo pelo qual nesse trabalho também é adequada a abordagem 
acerca da preclusão.

A estabilidade como uma exigência de segurança jurídica inclusive encontra amparo constitucional, posto que em seu art. $5^{\circ}$, há a expressa determinação no sentido de que a lei não prejudicará o direito adquirido, o ato jurídico perfeito, a coisa julgada. Portanto, quando se trata de segurança, não é uma referência apenas ao resguardo da vida, da moral, da integridade física das pessoas, mas também a necessidade de proteção ao ordenamento jurídico para que assim se alcance a segurança jurídica da forma como se espera.

A segurança jurídica, portanto, forma um dos fundamentos do Estado Democrático de Direito, tendo em vista que não é possível falar em democracia numa situação em que os atos jurídicos e decisões judiciais se alternem a todo momento sem seguir um padrão para casos concretos semelhantes.

Desse modo, partindo-se de um estudo breve sobre a preclusão, que é a perda do direito de se exercer um ato jurídico e tecendo as modalidades de preclusão, estuda-se a coisa julgada, que é o grau máximo de estabilidade do ato jurídico e a qual se subdivide em coisa julgada formal e coisa julgada material.

A coisa julgada material é ainda mais estável do que a primeira, pois só a partir de um estudo mais aprofundado sobre a coisa julgada é que será possível avançar no estudo sobre a ação rescisória propriamente, já que essa é uma ação que aplicase a algumas situações específicas e previamente elencadas nas quais já não cabe mais recurso, ou seja, em decisões em que ocorreu o trânsito em julgado.

Assim, o instituto da ação rescisória tomou destaque ainda maior em nosso ordenamento com o advento do CPC/2015, o qual acabou por ampliar o taxativo rol de cabimento de sua aplicação

Nesse sentido, a ação rescisória sendo uma ação autônoma de impugnação da decisão judicial pode vir no sentido de romper com a estabilidade que é o ideal do ato jurídico, entretanto o presente artigo objetiva analisar se em que pese haja esse rompimento com a estabilidade, se de fato há ou não prejuízo da segurança jurídica com a aplicação da ação rescisória.

\section{Metodologia}

$\mathrm{O}$ artigo em comento foi realizado a partir de pesquisa exploratória por intermédio de levantamento de informações sobre o tema, mormente o método teve como base pesquisa bibliográfica, posto que consoante José Carlos Köche (2011, p. 122), a pesquisa bibliográfica é imprescindível para que se possa realizar tanto a pesquisa descritiva quanto a experimental.

Assim, por meio de premissas lógicas extraídas da pesquisa bibliográfica, são trazidos no artigo aspectos sobre a questão da estabilização das decisões judiciais.

\section{Resultados e Discussão}

\subsection{Estabilização}

A estabilização trata-se de um fenômeno, configurando-se uma exigência de segurança jurídica, uma vez que os atos jurídicos tendem a adquirir essa estabilidade.

Conforme Câmara (2015, p. 299-300), o fenômeno da estabilidade atinge tanto os atos jurídicos de direito privado, a exemplo do que ocorre num estatuto de sociedade anônima, um contrato, os quais não podem ser alterados pura e simplesmente, bem como atos jurídicos de direito público, a exemplo do que acontece com decisões judiciais, atos administrativos e etc, sendo certo que a estabilidade pode se dar por diferentes graus, o que equivale a dizer que há atos mais estáveis do que outros.

Para a estabilidade do ato processual, podem ser elencadas três formas de se conferir: a preclusão, a coisa julgada e a estabilização. 
A estabilização encontra previsão no art. 303, do CPC que trata da estabilização da tutela antecipada e também no art. $357, \S 1^{\circ}, \mathrm{CPC}$, o qual trata da estabilização da decisão de saneamento e organização do processo.

As partes possuem, após a decisão que declara saneado o processo, cinco dias para pedir ajustes ou esclarecimentos, conforme estabelece o mencionado art. $357, \S 1^{\circ}$, CPC, e com isso, torna-se impossível voltar a tratar do teor da decisão no mesmo grau de jurisdição, tendo em vista, ainda, que a situação não comporta agravo de instrumento, exceto quanto dispor sobre distribuição do ônus da prova, cabendo as partes apenas a apelação caso queiram discutir a decisão.

Esse fundamento é essencial para o devido processo legal, e a sua própria organização, uma vez que há a fase introdutória para cognição do objeto, a fase principal que cuida da instrução probatória com o julgamento da lide, assim, a decisão precisa possuir certa estabilidade, de modo que o processo se desenvolva em tempo adequado para que se chegue a um resultado dentro desse tempo.

Deveras, justifica-se tal pretensão uma vez que, diante do conflito de interesses entre as partes, muito mais importante do que ter uma resposta do Poder Judiciário à altura de suas necessidades, as partes clamam para que a referida decisão, independente de seu teor, seja dotada de segurança jurídica e até certo ponto de imutabilidade.

Portanto, uma vez que se passe o prazo de cinco dias conferido às partes para que requeiram mudanças ou esclarecimentos, a decisão torna-se estável, de modo a vincular absolutamente o juízo de primeiro grau.

No que diz respeito à estabilização causada pela tutela antecipada, quando da decisão em que se concede a tutela antecipada não se interpõe recurso, a decisão continuará eficaz e apenas poderá ser repelida por processo autônomo em que haja decisão que a reveja, reforme ou ainda que a invalide, sendo certo que referido processo precisa ser aberto no prazo de dois anos contados do conhecimento da decisão que extinguiu o processo que deferiu a tutela antecipada.

Diante dos dois casos expostos, pode-se compreender que há dois níveis diferentes de estabilidade, porém, cabe destacar que nenhum desses níveis de estabilidade alcança o grau de estabilidade da chamada coisa julgada.

\subsection{Preclusão}

Trata-se da perda do direito de se exercer um ato processual. Como resultado dessa sempre ocorrerá uma estabilidade.

A preclusão tem como fundamento lógico a questão de que o processo é um fluxo continuado, que vai ao encontro da prestação da atividade jurisdicional, almeja, além de outros objetivos, ser efetivo e célere.

Nas lições de Assumpção Neves (2016, p. 906):

A preclusão é fenômeno que merece ser compreendido como a perda da possibilidade da prática de algum ato processual pelo transcurso de um prazo (preclusão temporal), pela sua prática incompleta ou equivocada (preclusão consumativa), ou pela prática de algum ato incompatível com o que deveria ter sido praticado (preclusão lógica).

Já nos dizeres de Bedaque (2010, p. 130):

A preclusão não se pode ver na atualidade como uma sanção, senão como uma limitação das faculdades das partes justificada precisamente na realidade desfavorável do processo (princípios de bilateralidade, contradição e igualdade de armas processuais). Resulta plenamente compatível com o princípio da audiência - audiatur et altera pars - que deve ser respeitado por todas as partes no processo, já que para evitar sua vulneração basta conter a possibilidade de contradizer ou ser ouvidas com independência de que a parte haja uso ou não desta faculdade.

Pelo entendimento de Bedaque, a preclusão configura-se como um fenômeno processual e não como uma sanção, ou seja, é fenômeno que diz respeito à organização do processo, sendo assim, possui uma natureza negativa pelo fato de não se constituir em sanção, ao passo que quando a preclusão caracteriza vantagem para a outra parte do processo, nesse sentido haveria de fato o viés positivo do fenômeno. 
Devemos salientar inclusive que a doutrina enumera vários tipos de preclusão, sendo as mais comuns a preclusão lógica, preclusão consumativa e a preclusão temporal, de modo que a partir de então pode ser feita uma breve análise dos tipos de preclusão para maior esclarecimento.

Portanto, a preclusão lógica ocorre quando o indivíduo perde a oportunidade de exercer um ato considerado incompatível com outro ato previamente praticado, e como exemplo dessa situação pode ser citado o caso de indivíduo que aceita a sentença em que perdeu o processo e depois resolve recorrer.

A preclusão consumativa acontece quando o sujeito não pode mais exercer um ato pelo motivo de já ter praticado esse mesmo ato anteriormente. Por exemplo, em face do princípio da unirrecorribilidade, não pode a parte vencida interpor dois recursos simultâneos contra a mesma sentença, exceto quando trata-se de interposição de recurso especial e recurso extraordinário, conforme dispõe o art. 1.031, CPC. E, de fato, cabe a preclusão consumativa em face dos próprios atos do magistrado, o qual não pode voltar a decidir sobre sentença na qual já ocorreu a estabilidade, sendo a decisão de saneamento e organização do processo.

Já a preclusão temporal diz respeito à perda do direito de praticar determinado ato processual justamente em razão da perda do prazo de exercê-lo.

Alguns autores mencionam também a preclusão por fases do processo (Rocha, 2011, p. 18), a qual ocorre no momento em que um ato processual se torna inviável quando o processo chegou a uma determinada fase que é incompatível com o ato.

Ainda, nos dizeres de Chiovenda (2002, p.406), "preclusão é a "perda ou extinção, ou consumação, o que se prefira dizer, de uma faculdade processual, pelo fato de terem sido alcançados os limites assinalados por lei para o seu exercício"

Enquanto a preclusão produz uma estabilidade endoprocessual, a coisa julgada produz estabilidade que se projeta externamente ao processo, a estabilidade exoprocessual.

Com esse entendimento percebe-se que em regra a lei proíbe, a nova prática de atos processuais que já praticados, ou que se deixaram de praticar, ou, até mesmo os atos que acabam contradizendo atos anteriormente praticados pelos sujeitos do processo.

\subsection{Coisa julgada}

A coisa julgada possui um conceito estabelecido pelo artigo $6^{\circ}$, parágrafo $3^{\circ}$, LINDB, o qual dispõe que: "Chama-se coisa julgada ou caso julgado a decisão judicial de que já não caiba recurso."

$\mathrm{O}$ artigo 502, CPC/2015 conceitua a coisa julgada como "denomina-se coisa julgada material a eficácia, que torna imutável e indiscutível a sentença, não mais sujeita a recurso ordinário ou extraordinário".

Nas palavras de Almeida (2013, p. 342):

Há que pontuar: toda demanda causa perturbação social, primeiramente porque o conflito não pôde ser resolvido aquém do judiciário, e também pela incerteza gerada pelo processo em aberto, enquanto não é resolvido. Isto nos remete ainda à necessidade de que os conflitos se resolvam em tempo hábil a estabelecer a paz social, já que processos que se prolongam por 20, 30 anos acabam perdendo a essência de pacificação, muitas vezes ocasionando mais tensão que a que havia antes do ingresso no judiciário.

Nesse entendimento, pode ser analisado que o autor encontra-se em condição de vantagem na ânsia de litigar e o réu em posição de desvantagem. A coisa julgada então surge como uma forma de se evitar esse ânimo pelo litígio.

Portanto, pode ser compreendido que o fundamento da coisa julgada está na segurança jurídica e no princípio da estabilização das decisões judiciais, uma vez que a regra no Direito Processual Civil brasileiro é de que as decisões judiciais são recorríveis, ou seja, contra a maioria das decisões cabe algum recurso, entretanto, a decisão judicial pode tornar-se 
irrecorrível em algumas situações, como por exemplo, com a perda do prazo para a interposição do recurso em razão da preclusão ou ainda depois de esgotarem todos os meios cabíveis.

Conforme esclarece Chiovenda (1998, p. 452)

A coisa julgada é a eficácia própria da sentença que acolhe ou rejeita a demanda, e consiste em que, pela suprema exigência da ordem e da segurança da vida social, a situação das partes fixadas pelo juiz com respeito ao bem da vida (res), que foi objeto de contestação, não mais pode, daí por diante, contestar.

Na mesma linha de entendimento, Bulos (2012, p. 633) esclarece que "a coisa julgada é uma qualidade dos efeitos do julgamento.

E prossegue esclarecendo que "consiste no fenômeno processual da imutabilidade e indiscutibilidade da sentença, colocada em abrigo dos recursos definitivamente preclusos e dos efeitos produzidos pela decisão judicial". Consequentemente, há presunção absoluta de que o direito foi aplicado corretamente ao caso concreto.

Por seu turno, Serra (2009, p. 3) aduz que:

A coisa julgada é instituto esculpido na Constituição Federal de 1988 e regulamentada mais minuciosamente no Código de Processo Civil. Traz a concepção de definitividade que deve ser conferida as decisões judiciais após transcorrido os prazos recursais ou esgotados todos os recursos legais cabíveis, o que petrifica a decisão, tornando-a, em regra, imutável e inatingível. Diante do superficial conceito explicitado, nota-se claramente que tal instituto está intimamente ligado com o P. da Segurança jurídica, estampado no art. $5^{\circ}$ XXXVI da Constituição Federal de 1988. A coisa julgada traz segurança ao titular da posição jurídica de vantagem, após ver seu direito ser tutelado em juízo.

Dessume-se que a coisa julgada conforme anteriormente salientado, encontra-se intimamente relacionada com a segurança jurídica que se espera no ordenamento processual, de tal forma que, não somente àquele que teve garantida a sua pretensão na decisão, como também aquele que permaneceu em situação de desvantagem, já que assim o mesmo pode repousar numa situação de tranquilidade no sentido de ter a certeza sobre aquele determinado fato que foi levado ao Judiciário.

No entendimento de Francesco Carnelutti (200, p. 406):

Res iudicata é, na realidade, o litígio julgado, ou seja, o litígio depois da decisão; ou mais precisamente, levando em conta a estrutura diversa entre o latim e o italiano, o juízo dado sobre o litígio, ou sejam, sua decisão. Em outras palavras: o ato e, por sua vez, o efeito de decidir, que realiza o Juiz em torno do litígio

Logo, temos o trânsito em julgado da decisão judicial quando esta passa de um estado de recorribilidade para irrecorribilidade, e depois de haver o trânsito em julgado, ocorre o fenômeno da coisa julgada, ou caso julgado, o qual consiste numa estabilidade ainda maior conferida à decisão judicial em questão.

Assim, a coisa julgada é a estabilidade da sentença que não admite mais recurso. Porém, deve ser mencionado que nem todas as sentenças alcançam essa mesma estabilidade, ainda que sejam irrecorríveis. Ademais, com o fundamento na estabilização das decisões judiciais, a coisa julgada acontece para que o litígio não dure eternamente, ou seja, no sentido de que a justiça possa colocar um fim àquele conflito.

\subsubsection{Coisa julgada formal e coisa julgada material}

A coisa julgada formal consiste na estabilidade que atinge determinadas sentenças terminativas que não resolvem o mérito da causa, trata-se de uma condição prévia da coisa julgada material (LIEBMANN, 2006, p. 57), e por isso podem acontecer simultaneamente a coisa julgada formal e material, mas nem sempre isso acontece e identifica-se pelo fato de o 
conteúdo da decisão judicial, que se torna imutável e indiscutível, ser uma questão formal, ou seja, há vícios relacionados com os pressupostos processuais e/ou as condições da ação.

De acordo com Vitagliano (2008, p. 64-65), a coisa julgada formal acontece quando cessarem todos os recursos que a lei processual prevê, seja porque foram usados todos esses recursos ou em razão do decurso do prazo para a sua interposição, ou seja, a coisa julgada formal é a imutabilidade da decisão dentro do mesmo processo em razão da ausência de meios de impugnação possíveis.

Já a coisa julgada material, dotada de estabilidade ainda mais forte do que a coisa julgada formal acontece quando na decisão o que se torna imutável e indiscutível é o próprio mérito, ou seja, a questão principal do processo, o qual é mostrado pelas partes ao juiz para que seja resolvido, de forma que o conteúdo dessa decisão não pode mais ser discutido seja em que processo for.

Conforme Nelson Nery Jr e Rosa Maria de Andrade Nery (2004, p.865), a coisa julgada material é a característica que torna imutável e indiscutível o comando que surge da parte dispositiva da sentença de mérito não mais sujeita a recurso ordinário, extraordinário, ou à remessa necessária.

Nos ensinamentos de Zufelato (2011, p. 27), a coisa julgada é dotada de finalidade muito prática e em decorrência de utilidade social, se faz necessário impor um limite à discutibilidade de uma decisão judicial, de modo que possa haver a certeza pela decisão no sentido de se evitar que haja uma eterna discussão sobre determinado assunto, razão pela qual somente a sentença de mérito vai ser capaz de transitar em julgado, tendo em vista ser a única que cumpriu o dever de se proporcionar um provimento jurisdicional, de forma que todas as demais sentenças que acabam não discutindo o mérito da questão são incapazes de adquirirem a imutabilidade.

Portanto, coisa julgada material possui estabilidade maior do que a coisa julgada formal em razão de que nem que seja sanado o vício seria possível demandar novamente.

\section{Natureza Jurídica da Ação Rescisória}

A ação rescisória tem natureza jurídica de demanda autônoma de impugnação das decisões judiciais transitadas em julgado, com o objetivo de desfazer um julgado, podendo até reabrir o mesmo para uma nova discussão.

Conforme ensinam Fredie Didier Jr e Leonardo Carneiro da Cunha (2016, p. 421):

A ação rescisória é a ação autônoma de impugnação, que tem por objetivos a desconstituição de decisão judicial transitada em julgado e, eventualmente, o rejulgamento da causa. Ela não é um recurso, exatamente porque dá origem a um novo processo para impugnar a decisão judicial.

Nas palavras de Carlos Henrique Bezerra Leite (2004, p.778):

A verdade, porém, é que a ação rescisória não se confunde com o recurso. Trata-se na verdade de uma ação, pois o recurso constitui um meio de impugnação de decisão judicial na mesma relação jurídica, isto é, "dentro" do mesmo processo, ao passo que a rescisória, embora também seja um meio de impugnação de decisão judicial, só se presta a fazê-lo e outra relação processual, ou seja, "fora" do processo em que se deu a decisão impugnada.

Neste diapasão, tanto os recursos como a ação rescisória são tidos como formas de impugnação, porém são distintos, na medida em que a ação rescisória não é um recurso em razão de que gera outro processo, ou seja, ela é interposta ao final de um processo em uma outra ação apenas depois do trânsito em julgado da última decisão judicial.

Mesmo versando sobre questões previamente debatidas, a ação rescisória realiza-se sendo discutida em processo distinto (apartado) daquele em que se está objetivando desconstituir a sentença. 
Assim, a ação rescisória necessita da coisa julgada, ao contrário do recurso, o qual impossibilita o trânsito em julgado. A coisa julgada material impossibilita que haja debate acerca de conteúdo já decidido, e a ação rescisória faz sumir a coisa julgada, reabrindo a possibilidade de se debater sobre o que já havia sido decidido em sentença, ou seja, a ação rescisória tira o obstáculo que é a coisa julgada, de modo que o conteúdo possa ser rediscutido.

Nesta linha de intelecção, a ação rescisória pode desconstituir a coisa julgada material, fenômeno que estabiliza as decisões judiciais, de maneira que estas se tornam imutáveis.

Portanto, a ação rescisória é demanda desconstitutiva, pois cancela a decisão proferida pelo juízo de primeira instância e o substitui pela decisão judicial do tribunal, a quem compete originariamente o seu julgamento, sendo dotada, a princípio, de eficácia ex tunc.

\subsection{Hipóteses de cabimento da ação rescisória}

O art. 966, CPC/2015 prevê as hipóteses de cabimento da ação rescisória, sendo que o inciso I estabelece seu cabimento quando a decisão for proferida por prevaricação, concussão ou corrupção do juiz.

O inciso II trata da decisão proferida por juízo impedido ou absolutamente incompetente, de modo que eiva de vícios o processo. É certo, ainda, que no caso de decisão colegiada, se um dos julgadores for considerado impedido e tenha proferido voto vencido, não deve haver a rescisão do julgado (Alvim, 2016, p. 324).

Já a terceira hipótese de cabimento da ação rescisória trata da possibilidade de ajuizamento da ação rescisória quando a decisão judicial de mérito resultar de dolo ou coação da parte vencedora em detrimento da parte vencida ou, ainda, de simulação ou colusão entre as partes com o fim de fraudar a lei.

Há também o cabimento de ação rescisória previsto no mesmo artigo pelos incisos seguintes, nos casos em que houver ofensa à coisa julgada; quando a decisão de mérito transitada em julgado violar manifestamente norma jurídica quando for fundada em prova cuja falsidade tenha sido apurada em processo criminal ou que venha a ser demonstrada na própria ação rescisória; quando o autor obtiver, após o trânsito em julgado, prova nova cuja existência ignorava ou de que não pôde fazer uso e que essa prova seja capaz, por si só, de lhe assegurar pronunciamento favorável, e a última hipótese versa sobre quando a decisão for fundada em erro de fato verificável do exame dos autos.

Nesse sentido, pode ser compreendido que a ação rescisória possui o objetivo maior de proteger o sistema jurídico, muito mais do que corrigir uma injustiça atribuída à parte lesada, pois ao analisarmos cada um dos incisos do art. 966, CPC, é possível notar que apenas o inciso VII, o qual trata do cabimento da ação rescisória quando o autor obtiver, posteriormente ao trânsito em julgado, prova nova cuja existência ignorava ou de que não pôde fazer uso, sendo o documento capaz de lhe assegurar pronunciamento favorável, possui o condão de proteger exclusivamente a parte.

Rodrigues, Fernandes e Bueno (2019) afirmam na mesma linha de entendimento que "Nesse ínterim, afastar a possibilidade de propositura de ação rescisória em face de decisão, mutatis mutandis, meritória, de cognição sumária e não exauriente, mas definitiva, eivada de vícios graves, seria, sobremaneira, prejudicial aos interessados e à ordem jurídica justa."

Os demais incisos do art. 966, CPC de fato procuram proteção ao ordenamento jurídico de modo a evitar que uma decisão seja proferida com o vício de impedimento ou incompetência absoluta do juiz, quando ofende a coisa julgada e as demais hipóteses de cabimento.

\subsection{Iudicium Rescindens e Iudicium Rescisorium}

Como parte do estudo introdutório da ação rescisória, compete-nos distinguir os juízos: juízo rescindente (iudicium rescindens) e o juízo rescisório (iudicium resciscisorium). Desse modo, compete ao tribunal, para processar a ação rescisória, exercer os dois juízos: Juízo de admissibilidade e juízo de mérito quanto ao pedido de rescisão da decisão, sendo este o juízo 
rescindente (que ocorre em todas as ações rescisórias) e, em alguns casos, ainda é necessário o juízo de rejulgamento da causa, que seria um terceiro juízo chamado de juízo decisório, o qual substitui aquele que for anulado, de tal forma que a decisão do juízo rescindente pode obstar o exercício do juízo rescisório, conforme explica Carvalho (2017).

O pedido de rescisão dá ensejo ao juízo rescindendo, que objetiva desconstituir uma decisão prolatada. Nesse caso, a natureza da ação será desconstitutiva negativa. Porém, caso haja igualmente o pedido de rejulgamento, o qual provoca o juízo rescisório, a natureza da ação será consoante esse pedido: constitutiva, condenatória ou meramente declaratória.

Portanto, pode ser assimilado que que o juízo rescindente antecede o juízo decisório, e a depender da decisão proferida e sede de juízo rescidente, pode obstar que seja exercido o juízo rescisório.

\subsection{A ação rescisória e a relatividade da segurança jurídica e da estabilização das decisões judiciais}

O primordial aspecto trazido à baila no que diz respeito à temática acerca da ação rescisória diz respeito justamente ao debate da estabilidade e harmonia do ordenamento jurídico e da questão da justiça, com opiniões respaldadas com argumentos convincentes dos dois lados. Os primeiros creem principalmente na ideia da segurança, preterindo este conceito ao da própria justiça, já os últimos defendem a permanência da justiça ao invés do conceito de segurança jurídica. Deve ser salientado que ainda que haja divergência de pensamentos e opiniões, os que defendem um dos conceitos não condenam totalmente o outro lado, apenas dão maior importância e destaque ao que se encaixa em sua teoria.

Graças ao fato de que os indivíduos podem ter acesso à informação acerca de como uma determinada Corte julga um caso, é que este indivíduo vai poder determinar se vai abrir ou não um processo, ele vai avaliar se é recomendável ou não, graças a jurisprudência e etc., que permite uma certa previsibilidade; de outro lado, a estabilização da decisão judicial, temos que ela torna o sistema muito mais coerente e adequado, sem a necessidade de refazer decisões a cada instante.

Com a formação da coisa julgada, não é mais possível alterar a demanda ou tornar a discuti-la na maioria dos casos, gerando a esperada segurança jurídica para todas as partes envolvidas no processo.

A ação rescisória trata principalmente sobre a relativização da coisa julgada, consoante já ressaltado. A relativização da coisa julgada e o entendimento do ponto contraditório torna possível a compreensão acerca do fundamento e natureza jurídica da rescisória. A fundamentação da rescisória é a própria relativização, uma vez que não deve ser conferida tamanha força e impacto a uma decisão de mérito transitada em julgado se essa estiver atingida de algum defeito previsto no rol taxativo do $\mathrm{CPC} / 2015$.

Assim, o estado de segurança jurídica é um ideal esperado, porém pode ser relativizado em determinadas situações, como são os casos em que cabe a ação rescisória, posto que é muito mais interessante que as decisões que são eivadas de vícios sejam corrigidas de modo que assim possa se alcançar o estado ideal de segurança jurídica e estabilidade de forma a se resguardar o sistema jurídico. De nada adianta a decisão manter-se estável sendo carregada de defeitos. Isso não pode ser considerado segurança jurídica, e nesse sentido a ação rescisória vem para corrigir esses problemas, sendo cabível contra qualquer decisão de mérito.

\section{Conclusão}

Através desse estudo pôde ser compreendido que o ato jurídico possui meios de atingir a estabilidade, sendo eles a preclusão, estabilização e a coisa julgada, sendo certo que cada um desses institutos confere um grau de estabilidade distinto do outro, com importante destaque no que diz respeito a estabilidade pela coisa julgada.

$\mathrm{Na}$ mesma linha de entendimento, ao passo em que a coisa julgada faz com que o conflito entre as partes se torne imutável, restou evidente que tal compreensão acerca do tema não pode ser vista de forma absoluta, em razão de que determinados princípios e valores que cercam a sociedade acabam permitindo uma certa flexibilização do direito em casos 
específicos. De modo que a coisa julgada igualmente acaba flexibilizada em certas situações, conforme foi destrinchado no corpo do presente estudo.

Feito o estudo acerca da coisa julgada, ficou esclarecido que quando de sua ocorrência há o grau máximo de estabilidade que o ato jurídico pode atingir, de modo que apenas em situações pontuais e específicas a coisa julgada pode ser rompida, e nesse ponto tornou-se essencial o estudo da ação rescisória para que pudesse ser analisado se ela vem a prejudicar ou não a estabilidade das decisões judiciais.

A ação rescisória é de extrema relevância para o nosso ordenamento jurídico, tendo em vista que contesta decisões judiciais eivadas de vícios e que acabam impossibilitando a ocorrência de uma justiça justa e prejudicando o atendimento ao direito da parte. Desse modo, a ação rescisória é instrumento que contribui para uma tutela jurisdicional prestada de forma eficiente.

Ainda, é de se destacar que a ampliação das possibilidades do manejo da ação rescisória no CPC/2015 para que qualquer decisão de mérito possa ser impugnada, trata-se de uma inovação, um aprimoramento na verdade, de modo que haja ainda preservação de direitos e garantias fundamentais.

Por todo o exposto pode ser concluído que a ação rescisória é instituto muito relevante sobretudo no que concerne à proteção ao sistema jurídico, muito mais do que uma garantia de correção de injustiças, tendo em vista que por meio da ação rescisória é possível o desfazimento de uma decisão já transitada em julgado e da qual já não cabe mais recurso.

Deve ser lembrado que o rol de cabimento da ação rescisória previsto no art. 966, CPC, de forma que ainda que a decisão esteja eivada de vícios, sendo esses vícios alheios àqueles previstos no rol taxativo não há que se falar em cabimento da ação rescisória, tendo em vista o princípio constitucional da segurança jurídica.

Com a possibilidade de se corrigir os vícios de uma decisão judicial de mérito em novas hipóteses de cabimento da ação rescisória, o CPC está aprimorando o instituto, de forma que finalmente seja alcançada a tão esperada estabilidade da decisão judicial, ao mesmo tempo em que se alcança a segurança jurídica com igualdade às partes e de forma justa e garantindo a supremacia da Constituição e a prevalência de um devido processo legal.

\section{Referências}

Almeida, L. F. (2013). A extensão da coisa julgada no novo CPC e a extinção da ação declaratória incidental: uma medida de segurança jurídica. Revista eletrônica de direito processual. 342(12), 12. https://www.e-publicacoes.uerj.br/index.php/redp/article/view/8684/6556.

Alvim, A. (2016). Novo contencioso cível no CPC 2015. RT.

Brasil. (1998). Constituição da República Federativa do Brasil. http://www.planalto.gov.br/ccivil_03/constituicao/constituicaocompilado.htm.

Brasil. (2015). Código de Processo Civil. 〈http://www.planalto.gov.br/ccivil_03/_ato2015-2018/2015/lei/113105.htm>.

Bedaque, J. R. S. (2010). Efetividade do processo e técnica processual. (3a ed.), Malheiros.

Bulos, U. L. (2012). Curso de direito constitucional. (7a. ed.), rev. e atual. de acordo com a Emenda Constitucional n. 0/2012 - São Paulo: Saraiva.

Câmara, A. F. (2015). O novo processo civil brasileiro. Atlas.

Carnelutti, F. (2000). Sistema de direito processual civil. Classic Book.

Carvalho, S. A. (2017). Da ampliação do cabimento da ação rescisória no cpc de 2015 e a (in)segurança jurídica no sistema processual brasileiro. Revista Direito UNIFACS - Debate Virtual, n. 207.

Chiovenda, G. (2002). Instituíções de direito processual civil. Bookseller.

Chiovenda, G. Instituições de direito processual civil. (1998). Bookseller, 1998 com anotações de Enrico Túlio Liebman. Bookseller.

Jr. Didier, F., \& Cunha, L. C. (2016). Curso de Direito Processual Civil: meios de impugnação às decisões judiciais e processo nos tribunais. (13a ed.), Juspodivm, v. 3.

Jr Nery, N. \& Nery, R. M. (2004). Código de Processo Civil Comentado e legislação extravagante. (8a ed.), Editora Revista dos Tribunais. 
Research, Society and Development, v. 10, n. 14, e291101422067, 2021

(CC BY 4.0) | ISSN 2525-3409 | DOI: http://dx.doi.org/10.33448/rsd-v10i14.22067

Koche, J. C. (2011). Fundamentos de metodologia científica. Vozes.

Leite, C. H. B (1997). Curso de direito processual do trabalho, 1, (2a ed.), LTr.

Liebman, E. T. (2006). Eficácia e autoridade da sentença e outros escritos sobre a coisa julgada. Forense.

Neves, D. A. А. (2016). Manual de direito processual civil. JusPodivm.

Rocha, R. H. M. Preclusão do processo civil. (2011). Livraria do Advogado Editora, 2011.

Rodrigues, J., Fernandes. R. L., \& Bueno, F. F. (2019). Tutela antecipada antecedente: Estabilização x ação rescisória. Rev. Ciênc. Juríd. Soc. Unipar. Umuarama. 22(2), 241-255.

Serra, V. M. T. (2009). A coisa julgada inconstitucional. Revista EMERJ, p. 3, Rio de Janeiro. https://www.emerj.tjrj.jus.br/paginas/tra balhos_conclusao/2s eme stre2009/trabalhos_22009/ViniciusMirandaTallaridaSerra.pdf.

Zufelato, C. (2011). Coisa julgada coletiva. Saraiva. 